\title{
Communication Technology and Exchanging Financial Assets: A Historical Perspective
}

\author{
Elizabeth B. Booth \\ Eli Broad College of Business Administration, Michigan State University \\ 645 North Shaw Lane, East Lansing, Michigan, 48824, United States \\ E-mail: boothe@msu.edu \\ G. Geoffrey Booth (Corresponding author) \\ Eli Broad College of Business Administration, Michigan State University \\ 645 North Shaw Lane, East Lansing, Michigan 48824, United States \\ E-mail: boothg@msu.edu
}

John P. Broussard

CFA, FRM, PRM, Rutgers University, School of Business-Camden

227 Penn St., Camden, New Jersey 08102, United States

E-mail: john.broussard@ rutgers.edu

Received: October 25, 2014 Accepted: November 6, 2014

doi:10.5296/ber.v4i2.6643 URL: http://dx.doi.org/10.5296/ber.v4i2.6643

\begin{abstract}
In recent years high frequency trading (HFT) in the financial markets has gained the attention of practitioners, regulators and even the general public. The existence of this type of trading is the direct result of the development of computer technology that permits information to be processed and trades made faster than humans can think. The purpose of this paper is to place the discussion of the role of this type of trading in a historical context. We accomplish this task by examining two abrupt technological changes that dramatically increased the speed at which information can be communicated and acted upon, i.e., the change of transportation based
\end{abstract}


communication to telegraphy (electromagnetic) and telegraphy to computer (electronic). This examination permits us to consider more broadly the role of financial markets in society. We argue that, as they have in the past when confronted with extreme change, high frequency traders and investors will learn to co-exist but only if new rules of the game are established and new data analysis and risk management techniques developed.

Keywords: High Frequency Trading, Communication, Information, Microstructure, Technology, Speed

\section{Introduction}

On May 6, 2010, U.S. based equity products experienced an unprecedented drop and recovery in prices, an event that was subsequently dubbed a "flash crash". ${ }^{1}$ As a result, high frequency trading (HFT) and to a lesser extent its parent, algorithmic trading, became subject to a great deal of attention by the popular media. Algorithmic trades are automated orders that are based on predetermined rules and executed by a computer, while HFT is a subset of this type of trading in which positions are taken by traders to exploit market situations or inefficiencies in the market that exist only for very short periods of time (often less than a second). The profitability of this type of trading obtains by effectively using the technical architecture of the computer network and the microstructure rules that are programmed into its software. In recent years, HFT has increased dramatically. For instance, it currently accounts for roughly two-thirds of the volume on U.S. stock exchanges and almost one-third of the transactions made on several popular foreign exchange trading platforms.

In a recently published book, Flash Boys: A Wall Street Revolt, Lewis (2014) asserts that financial markets are rigged to favor high speed traders. His thesis is that these traders prey upon those investors who do not have access to the costly high-speed trading platforms. His attack on HFT rests on the notion shared by most practitioners and academicians who study the behavior of financial markets that the prices of traded assets are determined largely by information. It has become a truism that traders with information have a better chance of securing profits than those that do not. Thus, for Lewis (2014) traders using HFT strategies have an unfair advantage because they can benefit from information accessible only to those with the highest speed currently attainable.

An important function of financial regulation, whether it is government initiated or self-imposed is to ensure that the market is fair. In this context, fair means that all market participants have access to the information that may determine an asset's price. It also means that this price cannot be manipulated. Because HFT strategies leverage technology with speeds

1 The event occurred between 2:30 p.m. and 3:00 p.m. EDT and was preceded by hours of turmoil and bad news. Major indexes dropped 5\% to 6\% prior to recovery, and many stocks exhibited much larger drops. Moreover, the prices of a few stocks behaved weirdly with some trading as low as $\$ 0.01$ and as high as $\$ 100,000$. It is believed that the flash crash, a label given to the event reflects the severity and speed exhibited by the price movements, was caused by the activation of a large sell order under the auspices of an algorithm that based its instructions only on volume and ignored price and time. The associated transactions then caused a slew of HFT programs to engage, which eventually caused prices to continue their downward spiral. Built in automatic stop trading procedures (circuit breakers) halted the market, giving the participants time to reflect. The contagion was contained and prices moved back to the levels prior to the crash. A detailed description of this event and its analysis is provided by the U.S. Commodity Futures Trading Commission \& U.S. Securities and Exchange Commission (2010). 
approaching that of light, as well as exceeding the limits of human comprehension, it is no surprise that the U.S. Department of Justice and the New York Attorney General's Office are investigating HFT to determine if any extant laws have been broken, and the U.S. Securities and Exchange Commission is exploring the possibility of new regulations or the modification of existing rules. ${ }^{2}$ In addition, several large investors initiated law suits against major U.S. exchanges as well as dark pools. ${ }^{3}$

In current parlance, the phenomenon of all the participants not having all of the relevant information at the same time is usually referred to as asymmetric information. Although the term is relatively new, the phenomenon has existed since the invention of markets many millennia ago. Nevertheless, the nature and characteristics of asymmetric information have evolved over time as a result of changing information and communication technologies. The change in relevant technology, however, is characterized by two abrupt changes: 1) the change from transportation based communication to telegraphy and 2) the change from telegraphy (electromagnetic) to computer (electronic).

The purpose of this essay is to briefly review the impact of these two technological changes on the markets for stock and other financial assets with emphasis given to the speed of information. We believe that viewing the matter through a historical lens may provide alternative insights to identify and evaluate market impacts, as well as provide opportunities to ask and to possibly answer questions, when judiciously evaluating the changed trading landscape. Benefits may accrue when wrestling with questions such as: Why is so much attention being given to these supposed "new" ways to trade? Have market participants created a revolutionary mechanism for information transfer and profitable trading strategies or are automated approaches simply just another step in the evolution of financial markets? Is there a need for new rules and regulations? If so, what types will promote fairness but not hamper trading?

\section{Role of Information in Financial Markets}

One of the primary functions of financial markets includes the efficient dissemination of information for effective price discovery and this is accomplished through trading. Generally, information can be classified as being exogenous or endogenous. In the context of a stock market, exogenous information might include a change in central bank policy, replacement of a firm's top management personnel, periodic earnings announcements, and other items occurring

${ }^{2}$ Rogers, Skinner \& Zechman (2014) and Jackson \& Mitts (2014) report that parts of the current information dissemination process used by the U.S. Security and Exchange Commission may provide unfair advantages to the high frequency traders. Moreover, regulators in many other (especially European) countries are focusing on this issue in the context of their markets. Germany has been in the forefront of this initiative. For instance, on February 28, 2008 the German Parliament passed the Act for the prevention of Risks and Abuse of High Frequency Trading (Entwurf eines Gesetzes zur von Gefahren imd Missbräuchen und Hochfrequenzhandel), which addressed HFT and algorithmic trading in general. This law, among other things, requires HFT firms to be licensed, to be restricted from using certain trading methods, and to operate under the auspices of the German Banking Act and the German Securities Trading Act. In addition, several European Union Directives have either been established or are being developed, e.g., Markets in Financial Instruments Directive (MiFID) and Market Abuse Directive (MAD).

${ }^{3}$ For instance the City of Providence (Rhode Island) and the State-Boston (Massachusetts) have recently sued (2014) several major exchanges and black pools alleging that the defendants not only provided trading information to HFT firms more quickly than they did to the plaintiffs but also they created complex investment instruments that gave sophisticated investors an unfair advantage. The plaintiffs hope that their complaint will turn into a class action suit. Noticeably, HTF firms are not party to the law suit. 
outside the borders of the market. In contrast, endogenous information is knowledge derived within the market itself and often reflects market participants' view of the exogenous information to which they are privy. Endogenous information can be manifested through such factors as turnover, bid and ask prices and the location of these prices in the trading queue, recent stock price movements, and other pieces of information generated internally.

Nevertheless, the speed at which information arrives is not all that matters. Information must be declared pertinent before transmission, assessed and interpreted upon receipt, and then a transaction executed, or not, that reflects the information and its interpretation. Each of these components requires a segment of time. The speeds of the first two segments are determined by the senders' and receivers' skill sets. The speed of the third depends on the architecture of the market where the trade is executed. Market architecture consists not only of the market's physical hardware, but also the rules and regulations that govern the behavior of the market's participants, as well as the form transactions are permitted to take.

Changing information and communication technology plays a crucial role in the availability of information, the speed at which it is transmitted as well as the speed of any resulting transaction. To better understand the social and economic impacts associated with the HFT environment, we compare and contrast the new electronic computer based technology to two earlier forms, i.e., transportation and telegraphy, with respect to the speed in which information flows to and within financial markets.

\section{Transportation Based Technology}

Transportation based communication has existed in one form or another since the beginning of human travel and was the only communication technology available until the early $19^{\text {th }}$ century. Although its efficacy waxed and waned over the centuries, a sophisticated commercial system was in effect during the Renaissance in the city-state of what is now Florence, Italy. This system serves as a useful example of what we now consider ancient and rudimentary communication technology.

Florence is not only associated with a rebirth of the art and philosophies of the ancient Roman and Greek societies, but also it is where most historians believe commercial capitalism, the precursor to today's capitalism, originated. In the $14^{\text {th }}$ and $15^{\text {th }}$ centuries Florence built a prosperous economy based on importing and exporting of cloth in its various stages of production. The market for these goods extended throughout what is now known as Europe and parts of the Mediterranean basin that were then commonly referred to as the Levant and Maghreb. Manufacturing and distribution was supported by a financial infrastructure ruled by merchant banks such as the one run by the Medici family, which, as de Roover (1963, p. 49) points out, operated branches and employed agents throughout the then-trading world. These banking networks were populated by members of the primary owner's extended families and close friends, who Kranton \& Minehart (2001) dub "fictive" kin.

As part of their support function, these banks engaged in foreign exchange arbitrage by issuing bills of exchange payable at a specific foreign location at maturity, and then reversing the transaction with a bill that was payable, at maturity, at a home location. The primary purpose of 
these bills was to facilitate commerce between geographically distant city-states, but sometimes the bills were used to avoid usury. In the latter case, merchandise was not involved and the transaction was considered a "dry exchange". In either case, communication among the agents in the various locations depended on physical travel by land or sea, and was often delegated to couriers in the agents' employ. Regardless of who made the trip, journey, and thus communication, times could be long and varied. These uncertain travel times made it difficult to predict the profitability of the transaction because the exchange rates on which they were predicated were often out of date.

This staleness problem was solved by creating the practice of usance, which was an agreed upon representative time that it took to travel between two specified locations. These times were published in merchant manuals such as the one provided by da Uzzano (1442) and were undoubtedly based on some sort of land and sea travel and considered such factors as the possibility of seasonal storms, the state of the transportation infrastructure, and perhaps the impact of armed conflict between warring parties - a common occurrence during this time. The usance, for example, between Barcelona and Bruges was 30 days and between Florence and London was 90 days. The bill's maturity date, then, was determined by adding the usance between the locations involved in the transactions to its issuance date. According to Booth (2009), not only were these arbitrage transactions profitable on average, but often agents sent news concerning their local economy and other items of interest with the bill. All correspondence was, of course, handwritten and directed to the attention of the recipient only.

\section{Telegraph Technology}

What is often forgotten in the analysis is that the technology of communication and information transfer remained largely transportation based for the next four centuries. ${ }^{4}$ The time required to travel between geographic locations was a constraint on the amount of time to send and receive information. Glacier-like communication speeds by today's standards continued until the telegraph was perfected around the middle of the $19^{\text {th }}$ century. Telegraph technology replaced transmission of information requiring physical delivery with transmission of messages using electric impulses through wires, which were usually installed along transportation routes. Communication was controlled and provided by a skilled technician using a hand device to interrupt an electric current to create a pattern that results in the dots and dashes associated with Morse code. Centralized telegraph offices were established in cities and towns, and couriers were often used to channel the messages, including stock prices, to and from a telegraph office and the local user. ${ }^{5}$

${ }^{4}$ Exceptions include line-of-sight signaling devices and carrier pigeons. The latter deserves special mention. According to folklore, the Rothschild banking family used pigeons to send messages to its various offices and agents. Supposedly, a Rothschild agent who was at the Battle of Waterloo in 1815 sent a message by pigeon post to the bank's London office that the British had defeated Napoleon well before the official notice arrived. The tale continues by indicating that the head of the London branch, Nathan Rothschild, acted on this private information and began to buy British government bonds in order to profit from their potential upcoming price increase brought about by the British win. Another version of the story has Rothschild selling small amounts while his agents did the massive buying, thereby keeping his bank's strategy hidden. Although this story may not be completely true, pigeon post is technically feasible. Walcott (1996) reports that experiments have shown that pigeons can indeed find their way to their home loft regardless of the time of day, although there is disagreement on how they are able to do this.

5 The telephone, which was invented in 1874, extends basic telegraphy in two primary ways. First, it converts sound into an electric signal that can be transmitted through wire and then turned back into sound at the end of the wire. 
As a result, message transmission speed increased dramatically. For example, according to Garbade \& Silber (1978), telegraph connections between New York and Philadelphia stock markets in 1846 shortened the delay of knowing the price of securities in the other market from one day to the close of the home market on the same day. Similarly, the use of the telegraph in 1848 connecting New York and New Orleans foreign exchange markets reduced the information lag between the two markets from $4-7$ days to one day or less. They also find that the establishment of the transatlantic cable in 1866 permitted individuals in New York to know bond prices in London in a single day rather than in three weeks or more. In addition, telegraph printing machines were developed in the 1860 s and by the 1880 s, these ticker tape units were installed in many brokers' offices, enabling them to obtain stock price almost as soon a trade was executed.

Carey (2009) argues that telegraph technology not only changed the way people communicated with one another but also changed the way society viewed time and space. For the first time, there was an effective separation of communication from transportation. Writing became condensed and news stories contained only the basic facts. Carey (2009, p. 157) opines that "...the telegraph freed communication from the constraints of geography". He suggests that the increased speed of information transmission resulted in a decline of arbitrage opportunities between distant markets because it reduced spatial uncertainties. He also suggests that this new technology encouraged the development of futures contracts and the establishment of the Chicago Mercantile Exchange (CME) because more information concerning beliefs about the future was available. Much of this impact was anticipated by Samuel F.B. Morse, who in 1839 wrote that he expected his invention would eventually permit information to be spread throughout the land, "...making in fact one neighborhood of the whole country" (Czitrom, 1982, pp. $11-12)$.

\section{Computer Technology}

The next major leap in information technology occurred in the 1940s, and is still being refined today. Starting with ENIAC (Electronic Numeric Integrator and Computer), a huge machine that took up to 1,800 square feet of floor space and used vacuum tubes, the technology evolved to central processing units containing memory, logic and circuits on smaller and smaller chips. These physically smaller units were often linked together by connections of various types, with wireless connections possible. Transmission speed increased dramatically in the ensuing years, and as a consequence, new terms describing this speed were added to the communication technology lexicon.

The notion of "transmission speed" was transformed from the distance a message traveled to be delivered per unit of time into "latency", the time it takes (delay) to deliver a message. Messages now typically travel through networks consisting of various devices such as switches, gateways and routers that guide information from its origin to its ultimate destination. Network latency is typically defined as the time it takes (delay) for an information packet to travel from the sender host to the receiver host. Theoretically this delay (called such because the ideal

This eliminated the need for a tedious code as well as code senders and receivers. Second, the telephone, even in its rudimentary form, was more flexible that the telegraph and could be located more easily in the offices of financial firms and in the various trading venues, thereby providing somewhat faster access to information. 
transmission speed is instantaneous) is determined by the distance between the sender and receiver hosts and system's bandwidth. Bandwidth is a measure of the maximum throughput of the network and is limited by the speed of light (approximately 186 thousand miles per second in a vacuum). ${ }^{6}$ Kay (2009) reports that current technology limits latency's duration to around $70 \%$ the speed of light, which means that information travels at the speed of 130 thousand miles per second. Moreover, he indicates that latency varies and is characterized by spikes and bursts. This phenomenon, referred to as jitter, results from irregular delays throughout network components.

To put these latency values in perspective, consider the time it takes to send information from Chicago to New York City using a modern computer network. Kay's (2009) simulations indicate a round trip latency of 39.2 milliseconds. ${ }^{7}$ Laughlin, Aguirre, \& Grundfest (2014) find that between April 2010 and August 2012 the time for one-way communication between Chicago and New York decreased by three milliseconds. They attribute this decrease to the addition of a latent-optimized fiber optic connection in the network and the use of line-of-site microwave networks. Bowie (2014) reports that in January 2014 a fiber link was established connecting NYSE Euronext's Mahwah (New Jersey) facility to key Chicago recipients with a roundtrip latency of around 14 milliseconds or roughly the equivalent of 55\% the speed of light. Even more recently, Westbrook et al. (2014) indicates that it is possible using microwave technology to achieve a one-way latency between the CME's data center, located in Aurora (a suburb of Chicago), and New York of five milliseconds.

Many believe that even several millisecond delays are too slow. To accommodate this belief, major computer network trading centers are leasing computer space to those firms and individuals that require the fastest speed possible. ${ }^{8}$ This practice, called co-locating, not only greatly reduces latency to the trading network but also often provides the participants the

${ }^{6}$ This limit holds under Newton's Third Law of Motion and Einstein's Special Theory of Relativity. Faster speeds are consistent, however, with Einstein's General Theory of Relativity. Although the ability to fold space and use worm holes to permit matter to travel faster than the speed of light is exploited in the science fiction literature (e.g., the Dune series initiated by Frank Herbert), the technology to engage in this behavior is well beyond the scope of today's engineering knowledge. Faster than light speeds are also consistent with quantum mechanics in the context of entangled photons. Although speeds of this magnitude may be physically possible, as demonstrated by Yin et al. (2013), many scientists doubt if such a setup can ever be used to transmit useful information.

7 At the present time, according to the Systéme International d'Unité's, the "second" is the agreed upon fundamental measure of time and is currently measured in terms of the radiation of a cesium-133 atom located at sea level. Originally it was linked to the time it took for the earth to complete one rotation. This rotation was labeled one day. Sometime between 1500 and 1000 BCE the Egyptians, using a duodecimal number system, divided the day into two 12 hour periods. Circa 150 Ptolemy used the Sumerian sexagesimal system, which was developed in the fourth millennium BCE, to divide the hour period into 60 equal parts and then further divided each of these parts into 60 equal parts. He labeled the first division partes minutae primae and the second division partes minutae secundae. The term "second" is derived from the Latin secunda. For ease of reference, seconds are often expressed in powers of 10 and named accordingly. For example, a megasecond (Ms) is $10^{6}$ seconds, a kilosecond (ks) is $10^{3}$ seconds, a millisecond ( $\mathrm{ms}$ ) is $10^{-3}$ of a second, and a microsecond $(\mu \mathrm{s})$ is $10^{-6}$ of a second. To put these times in perspective, a kilosecond is one million times larger than a millisecond.

8 An alternative is to construct a trading platform that internally controls the effective latency. For example, IEX, a dark pool (a.k.a. an alternative trading system) that has recently petitioned the U.S. Securities and Exchange Commission to gain exchange status, installed a coil (38 linear miles) of fiber optic cable as a buffer between the customer's platform entry point in New Jersey and IEX's matching engine. This added 700 microsecond roundtrip latency to reduce the probability of front running and stale quote arbitrage by its HFT customers. This action is reminiscent of a maneuver by the NYSE in 1894. According to Emery (1896, pp. 138 - 139), by that time the telephone had erased any informational advantages between major cities in the U.S. and brokerage business was gravitating from New York firms to Boston firms. In response, the NYSE banned the use of telephones on the exchange floor but permitted them off the floor. Their relocation gave the New York brokers a 30 second advantage and business returned to New York. 
opportunity to directly connect with each other. By way of example, suppose the trader's computer connecting transmission lines are approximately 500 feet one way. At the speed of light the round trip latency is roughly one microsecond. Using today's fastest technological setup, this latency would increase to approximately 1.4 microseconds. ${ }^{9}$ The demand for such services is growing and the entities that provide co-location services have expanded, causing exchanges to consider the availability and costs of real estate and utilities. Communication technology is again subject to the constraints that impacted Renaissance commerce: geographic proximity and routes traveled are determining factors for effective communication transfer.

\section{Technology and Human Latency Comparisons}

To compare the time delays experienced under various communication technologies (i.e., transportation, telegraph, computer, etc...), it is useful to adopt a common network and unit of measurement. From the previous discussion, the most recent one-way latency estimate between Chicago and New York City using a computer driven network is approximately seven milliseconds. If the telegraph is used instead the latency increases to slightly less than 10 hours or about 35 kiloseconds. If the Chicago to New York City distance is traveled by sequential couriers on horseback, the latency is in the neighborhood of 62 hours or roughly 227 kiloseconds. ${ }^{10}$ Stated somewhat differently, the change from information conveyed by physical transportation to the telegraph decreased the latency by around $85 \%$. The decrease is noteworthy but pales when compared to the $99.99998 \%$ decrease (i.e., the change from 35 kiloseconds to seven milliseconds) in latency when the computer replaced the telegraph as the preferred method of communication between financial markets.

The typical response time of humans to simple stimuli such as light and sound is around 200 milliseconds. Simple stimuli, however, are weak proxies for the signals to which a sophisticated trader might have to react. A more reasonable comparable cognitive exercise would be a chess grandmaster recognizing that her king is in danger of being mated. Saariluoma (1995, p. 43) reports that recognizing this possibility takes 650 milliseconds, or about the time it takes for a person to blink her eye three times. Consider the required accuracy of measurement required for trading in today's financial markets. According to Kay (2009), measurement accuracy of 100 milliseconds is needed for low frequency trading (LFT). In contrast, HFT requires one millisecond or less. However one views stimuli response time, HFT time domains push the limitations of human comprehension capabilities.

\section{Impact of HFT (aka Low Latency Trading)}

In the last few years, numerous empirical studies have investigated the impact of HFT specifically and algorithmic trading generally on stock markets in the U.S (e.g., Castura et al.,

\footnotetext{
${ }^{9}$ If the speed of light cannot be exceeded, the agglomeration of facilities cannot be avoided since HFT between Mahwah and, say, San Francisco would incur a speed of light roundtrip latency of approximately 32 milliseconds.

${ }^{10}$ The computer based latency delay is one-half the round trip latency reported by Bowie (2014) The telegraph latency is estimated by using the smallest per mile latency associated with the New York City to New Orleans transmission and the straight line distance between New York City and Chicago (approximately 710 miles). Transportation latency is calculated using the current road mileage and a round trip of 790 miles plus average pony express speed of 12.5 miles per hour.
} 
2010; Hasbrouck \& Saar, 2013; and Hendershott, Jones \& Menkveld, 2011). Studies have also been conducted on many other equity markets ranging from Amsterdam to Warsaw (e.g., Boehmer, Fong \& Wu, 2014; Boehmer \& Shankar, 2014; Hendershott \& Riordan, 2013; and Riordan \& Storkenmaier, 2012), futures markets (Karagozoglu, 2011) and foreign exchange spot markets (Chaboud, et al., 2014). These studies, and others not cited, generally show that the quality of markets has improved when measured by such metrics as decreasing spreads, increasing displayed depth in the limit order book, and lowering short-term volatility. As succinctly stated by Hendershott \& Riorden (2013) these benefits are the result of trading algorithms “...placing more efficient quotes and demanding liquidity to move ... prices towards the efficient price." Boehmer \& Shankar (2014), report that increased algorithmic trading also tends to reduce commonality in order flow, returns, liquidity, and volatility experienced by the various traders. They attribute their findings to increased competition among algorithmic traders.

Are these benefits able to be achieved without the assumption of risk? There is some evidence that new risks emerge at ultrafast speeds. Johnson, et al. (2013) report the presence of "ultrafast extreme events (UEEs)," a label that they give for stock price changes that occur at frequencies below one second. They observe positive spikes and negative spikes (crashes) throughout a trading day, and report that these UEEs, or jitter in Kay's (2009) terminology, do not appear related to daily price volatility or volume nor is their pattern of occurrence explained by regulation. Moreover, at speeds above the human latency, the probability of an UEE occurrence seems to be well-explained by power laws (e.g., a Generalized Pareto Distribution), which are the workhorses of today's extreme value statistics. In contrast, UEE observations below this human threshold do not appear to follow this law. ${ }^{11}$ Thus, high frequency traders may be faced with Knightian uncertainty (or ambiguity), i.e., they are unsure of the probability model that dictates their operating environment. By themselves, however negative UEEs may not be overly harmful to low frequency traders, but if they build on each other, the end result may be a flash crash or worse. ${ }^{12}$

\section{Coexistence of HFT and LFT}

The strategies that are currently being used include those that exploit the presence of a micro-spread, the position of an order in the queue, the response to the arrival of news that is measured in microseconds, the exchange's microstructure rules, and capture of rebates associated with some types of orders. The application of these strategies has led to various trading practices that have been given colorful names. For example, "spoofing" is the practice of placing buy and sell orders in an attempt to manipulate prices. "Quote Stuffing” occurs when a large number of orders is submitted either to slow down the trading system or to hide the submitter's true intent. "Momentum Ignition" obtains when a price trend is started or aided by

11 Brownlees \& Gallo (2006) suggest that it may be necessary to design new statistical tools to derive meaning from these data.

${ }^{12}$ It has become commonplace to refer to market crashes as black swan events. This label is derived from the often told example given to introductory college philosophy classes to describe the concept of falsifying a null hypothesis. It rests on the notion that if only white swans are repeatedly observed then all swans are white. If the null is "all swans are white", then an appearance of a supposedly rare black swan will serve to falsify it. Because negative UEEs are small relative to the crashes that have been named black swans, a more descriptive term for a UEE crash period appropriately measured in milliseconds should, perhaps, be a black cygnet (baby swan) event in recognition of its relatively small size. 
submitting orders in such a way that encourages others to follow. Finally, although not sporting a sobriquet, a commonly used trading practice is strategically to cancel orders so that they cannot be executed.

Can low frequency traders survive in a high frequency environment? O'Hara (2014) believes that they can, but they need to look at the world differently. They need to rethink the ways that they analyze data and they need to be aware of the risks associated with speed. Undoubtedly vendors will design programs to assist low frequency traders to meet the challenge. An example of this type of software is AlgoFast. According to the description provided in a Globe Newswire (2014) release this software, which is available to the retail investor through a cloud network, engages in automatic trading that is activated by specific preprogrammed events related to a wide array of business and economic indicators fed to it by various news agencies within milliseconds of their occurrence.

It is also useful to clearly distinguish the differences between trading and investing. Clearly, trading and its academic relative, market microstructure structure, involve short-term decisions and events, regardless of the technology in force. In contrast, investing is a long horizon activity. These activities have different purposes. The former is to provide a venue for financial asset holders to exchange immediately these assets in such a way that their current and future economic beliefs are more likely to be met or to exploit and eliminate unintended pricing irregularities caused by market microstructure rules and anomalies. The latter is to channel capital into productive opportunities that will not only increase an individual's economic worth but also enhance the well-being of her society.

Moreover, investors tend to view future stock prices in a coarser grid than do traders, i.e. dollars instead of pennies. ${ }^{13,14}$ As a result, investors tend to be much more concerned with the risk associated with the former since the scale of the risk associated with an investments terminal value is 10,000 times that related to the initial or final trade. This tendency is consistent with Aristotle (350 BCE, Bk. 1, Ch. 3) when he commented that "... it is the mark of an educated man to look for precision in each class of things just so far as the nature of the subject admits." Restated in today's vernacular, Dick (2014), based on his discussion with several traders, suggests that the investor would be better served if she ignored short term price fluctuations (especially HFT noise), lengthened her time horizon and considered taking liquidity.

Computer processing and speed is also important to the LFT. Markets and investment houses routinely create and disseminate large amount of data on a daily basis. This data creation is part of a societal data explosion that is typically referred to as "Big Data". This has led to new ways of thinking about data under the rubric of data analytics. Underlying this rubric are the needs to

${ }^{13}$ In April 2001 the U.S. National Market System's (NMS) Regulation 612 set the tick size for all NMS stocks at $\$ 0.01$ in response to the decision that stocks should be priced in decimals. In 2004 this regulation was modified so that for stocks trading at less than $\$ 1$, tick size became $\$ 0.0001$. Bartlett \& McCrary (2013) report that after this tick size reduction was made HFT increased for these less than $\$ 1$ stocks, although changes in various market quality measures were mixed. The U.S. Securities and Exchange Commission is currently considering a pilot program to increase the tick size of selected stocks in order to examine precisely the relationship between tick size and trading activity.

${ }^{14}$ This does not mean that high frequency traders avoid engaging in strategies that may result in dollars rather than pennies For instance, these traders may exploit the presence of limit orders by purchasing stock ahead of these orders and using the book to find a buyer of last resort if the market turns. 
acquire, process and then provide information not only in a usable form but also in a timely fashion for decision making. In view of the massive amount of data that is currently available to the LFT, such a system is required for them to make well-thought out investment decisions.

\section{Concluding Remarks}

O'Hara (2014, p. 25) maintains that "[m]arkets are not just faster; they are different" and that a new paradigm exists. We agree. It is apparent that trading speed and the ability to assess movement of information is quickly reaching its technological limit. It is also apparent that the behavior of asset prices is different at speeds faster than human comprehension. The phenomenon of co-location once again brings geography back into the mix in much the same way that the telegraph made it irrelevant, but its impact is much more nuanced.

Thus, in recognition of the race to ever-decreasing latency, it is of increasing importance that we re-examine the design of our financial markets. We need to address questions such as: What price precision (i.e., tick size) should be allowed? What rules should determine the queue position in the book? What type of orders should be permitted? What should be the cancellation protocol? What trading compensation scheme would allow the trading goals to be achieved? How can fair access be permitted to all appropriate parties? Even more generally, how do we keep the increase in market quality that is sometimes associated with HFT and avoid the unwanted consequences of market manipulation? Should procedures such as circuit breakers be used to halt trading under certain circumstances and, if so, how should they be formulated and implemented? What is the role of artificial intelligence in the trading process? What should be the role of human thought and activity in the trading process? ${ }^{15}$ The list is long, perhaps endless, but the questions must be addressed.

In thinking about these and related questions, however, we must also consider, as Friedman \& Nissenbaum (1996) point out, that computer software does contain human biases. ${ }^{16}$ In addition, Grief \& Laitin (2004), and many others, have suggested that societies create institutions and institutional arrangements that result in outcomes that can be characterized as a Nash equilibrium, which result in self-reinforcing behavior. ${ }^{17}$ Nevertheless, we also need to remember that financial markets are complex techno-social systems and, as Vespignani (2009) succinctly argues, require us to think in network terms about how information flows. He also points out that these types of networks do not always evolve as their human creators planned. Thus, any changes in market design must embed the ability to adapt.

Undoubtedly, the exchanges faced similar questions when facing a communications world

${ }^{15}$ Beunza \& Millo (2013) argue that floor traders (at least those on the NYSE) bring rationality to the market. This is because they have developed an informal code of conduct that has its roots in almost familial bonds partially as a result of traders being physically clustered by religious and other similar cultural backgrounds.

${ }^{16}$ It is generally accepted that humans have a tendency to focus on round numbers. For example, numerous studies demonstrate that prices tend to cluster on zeroes and fives (e.g., Harris, 1991, Booth, Kallunki \& Martikainen, 2000, and Ikenberry \& Watson, 2008, among others.) Thus, it is likely that this sort of bias is present in a trading algorithm. By way of illustration, a program may be written so that it awakes at the beginning of every second, then operates for 100 milliseconds and then sleeps for the next 900 milliseconds until it is awakened to begin the process all over again.

17 A Nash equilibrium obtains when no player in the game can gain an advantage by changing her strategy while other players keep their strategies unchanged. The condition is named after John Nash who was named a Nobel Laureate for his pioneering work in game theory. His life and scholarly achievements are the subjects of a 2001 biographical film A Beautiful Mind. 
reshaped by telegraph that, as pointed out by Thompson (1947), required changes in law, economic theory, and management techniques, among other things. In retrospect it appears that the inventor of this usable technology, Samuel F.B. Morse, was prescient when on May 24, 1844 he sent the first telegram using the newly constructed line that connected Baltimore and Washington, DC. Borrowing from the Bible, Numbers 23:23, he wrote: "What hath God wrought?"

This sentiment is pertinent today, and we believe that the current technological change is as game-changing as the introduction of the telegraph. Many current philosophers agree with this position. For example, Virilio (1994) suggests that the marriage of capitalism and the new media technology has created a culture of speed. Brey \& Sorakar (2009) indicate that the prevailing philosophical view is that current information technology has made capitalism (and by inference, the markets) more flexible and global with the ever changing network being the basic economic unit.

Nevertheless, in the last 170 years, the industry and its regulators have become more sophisticated and capable. Importantly, the intellectual and empirical understanding of how markets work and their role in society has become better understood. Thus, we believe that financial markets will meet the current speed challenge and high frequency traders and investors as well as other low frequency traders will find a way to coexist in a stable environment. In doing so, new rules of the game will have to be established and new risk management techniques developed. Of course, future changes in technology and society will impact the financial markets, but unless our current understanding of relativity and quantum mechanics changes drastically these changes probably will not involve the speed in which information can be transmitted. They will, however, increase the amount of information that is available and the ways in which these data are analyzed and interpreted.

\section{References}

Aristotle. (350 BCE). The Nicomachean ethics. Trns. by W.D. Ross. Internet Classics Archive. http://classics.mit.edu/Aristotle/nicomachean.html

Bartlett, R. P., \& Mc Crary, J. (2013). Shall we haggle in pennies at the speed of light or nickels in the dark: How minimum price variation regulates high frequency trading and dark liquidity. Working paper. School of Law, University of California - Berkeley, September 15.

Beunza, D., \& Millo, Y. (2013). Folding: integrating algorithms into the floor of the New York Stock Exchange. Working paper. London School of Economics. February 26. http://dx.doi.org/10.2139/ssrn2265849

Boehmer, E., Fong, K. Y. L., \& Wu, J. (2014). International evidence on algorithmic trading. Working paper. June 2. http://dx.doi.org/10.2139/ssrn2022034

Boehmer, E., \& Shankar, R. L. (2014). Low latency trading and the comovement of order flow, prices, and market conditions. Working paper. Stern School, New York University. April 4.

Booth, G. G. (2009). Foreign exchange profits in two early Renaissance money markets. Journal of European Economic History. 38. 123-145. 


\section{Macrothink}

Business and Economic Research ISSN 2162-4860 2014, Vol. 4, No. 2

Booth, G. G., Kallunki, J.-P., \& Martikainen, T. (2000). Internalization and stock price clustering: Finnish evidence. Journal of International Money and Finance. 19. 737-751. http://dx.doi.org/10.1016/S0261-5606(00)00022-X

Bowie, M. (2014). Spread connects NYSE Mahwah data center to Chicago. WatersTechnology, January 10.

http://www.waterstechnology.com/inside-market-data/news/2322105/spread-connects-nyse-m ahwah-datacenter-to-chicago

Brey, P., \& Soraker, J. H. (2009). Philosophy of computing and information technology. In A. Meijers (Ed.), Philosophy of technology and engineering sciences, Vol. 9 (pp. 1341-1407). Amsterdam: Elsevier. http://dx.doi.org/10.1016/B978-0-444-51667-1.50051-3

Brownlees, C. T., \& Gallo, G. M. (2006). Financial econometric analysis at ultra-high frequency: Data handling concerns. Computational Statistics and Data Analysis. 51(4). 2232-2245. http://dx.doi.org/10.1016/j.csda.2006.09.030

Carey, J. W. (2009). Technology and ideology: The case of technology. In Communication as culture: Essays on media and society, Rev. ed. (pp. 155-177). New York: Routledge.

Castura, J., Litzenberger, R., Gorelick, R., \& Dwivedi, Y. (2010). Market efficiency and microstructure evolution in U.S. equity markets: A high frequency perspective. Working paper. http://www.rgmadvisors.com/docs/MarketEfficiencyStudyOct2010.pdf

Chaboud, A., Chiquoine, B., Hjalmarsson, E. \& Vega, C. (2014). Rise of the machines: Algorithmic trading in the foreign exchange market. Journal of Finance. 69(5), 2045-2084. http://dx.doi.org/10.1111/jofi.12186

Czitrom, D. J. (1982). Media and the American mind: From Morse to McLuhan. Chapel Hill, NC: University of North Carolina Press.

Dick, D. (2014). Frequency jamming: Can investors outsmart high-frequency traders. CFA Institute, The Member Magazine for Investment Professionals (Sept./Oct.). 22-23.

Emery, H. C. (1894). Speculation on the stock and produce markets of the United States, Studies in history, economics and public law. New York: Columbia University Press.

Friedman, B., \& Nissenbaum, H. (1996). Bias in computer systems, ACM Transactions on Information Systems. 14:3. 330-347.

Garbade, K. D., \& Silber, W. L. (1978). Technology, communication and the performance of financial markets: 1840-1975. Journal of Finance. 33. 819-832. http://dx.doi.org/10.2307/2326479

Greif, A. \& Laitin, D. D. (2004). A theory of endogenous institutional change. American Political Science Review. 98(4), 633-652. http://dx.doi.org/10.1017/S0003055404041395

Globe Newswire. (2014). AlgoFast redefines the way individuals approach investing. Chicago, IL, June 26. newsdesk@globenewswire.com 


\section{Macrothink}

Business and Economic Research ISSN 2162-4860 2014, Vol. 4, No. 2

Harris, L. (1991). Price clustering and discreteness. Review of Financial Studies. 4. 389-415. http://dx.doi.org/10.1093/rfs/4.3.389

Hasbrouck, J., \& Saar, G. (2013). Low-latency trading. Journal of Financial Markets. 16(4). 646-679. http://dx.doi.org/10.1016/j.finmar.2013.05.003

Hendershott, T., Jones, C. M., \&.Menkveld, A. J. (2011). Does algorithmic trading improve liquidity? Journal of Finance. 66. 1-33. http://dx.doi.org/10.1111/j.1540-6261.2010.01624.x

Hendershott, T., \& Riordan, R. (2013). Algorithmic trading and the market for liquidity. Journal of Financial and Quantitative Analysis. 48(4). 1001-1024. http://dx.doi.org/10.1017/5002210901/3000471

Ikenberry D. L., \& Weston, J. P. (2008). Clustering in U.S. stock prices after decimalization, European Financial Management. 14, 30-54.

Jackson, Jr., R. J., \& Mitts, J. (2014). How the SEC helps speedy traders. Working paper. School of Law, Columbia University, November 8. http://ssrn.com/abstract=2520105.

Johnson, Ne., Zhao, G., Hunsader, E., Qi, H., Johnson, Ni., Meng, J., \& Tivnan, B. (2013). Abrupt rise of new machine ecology beyond human response time. Scientific Reports. September 11, 1-7. http://dx.doi.org/10.1038/srep02627

Kay, R. (2009). Pragmatic network latency engineering: Fundamental facts and analysis, Working paper. cPacket Networks Inc., Mountain View, CA. http://cpacket.com/wp-content/files_mf/introductiontonetworklatencyengineering.pdf.

Karagozoglu, A. (2011). Direct market access in exchange-traded derivatives: Effects of algorithmic trading on liquidity in futures markets. The Review of Futures Markets. 19 (special issue). 95-142.

Kranton, R. E., \& Minehart, D. F. (2001). A theory of buyer-seller networks. The American Economic Review. 91(3), 485-508. http://dx.doi.org/10.1257/aer.91.3.485

Laughlin, G., Aguirre, A., \& Grundfest, J. (2014). Information transmission between financial markets in Chicago and New York. The Financial Review. 49. 283-312. http://dx.doi.org/10.1111/fire.12036

Lewis, M. (2014) Flash boys: A Wall Street revolt. New York: W.W. Norton \& Company.

O'Hara, M. (2014). High-frequency trading and its impact on the market. Financial Analysts Journal. 70(3). 18-27. http://dx.doi.org/10.2469/faj.v70.n3.6

Riordan, R., \& Storkenmaier, A. (2012). Latency, liquidity and price discovery. Journal of Financial Markets. 416-437. http://dx.doi.org/10.1016/j.finmar.2012.05.003

Rogers, J. L., Skinner, D. J., \& Zechman, S. L. C. (2014). Run EDGAR run: SEC dissemination in a high frequency world. Chicago Booth Research paper No. 14-36, Fama-Miller Working paper. October 22. http://dx.doi.org/10.2139/ssrn.2513350

De Roover, R. A. (1963). The rise and decline of the Medici banks. Cambridge, MA: Harvard 
University Press.

Saariluoma, P. (1995). Chess player's thinking: A cognitive psychological approach. New York: Routledge.

Thompson, R. L. (1947). Wiring of a continent: The history of the telegraph industry in the United States 1832-1866. Princeton, NJ: Princeton University Press.

U.S. Commodity Futures Trading Commission \& U.S. Securities Exchange Commission. (2010). Findings regarding the market events of May 6, 2010: Report of the staffs of the CFTC and the SEC to the Joint Committee on Emerging Regulatory Issues. Washington, DC, September 3.

da Uzzano, G. A. (1442 circa). La pratica della mercatura. In G.F. Pagini, 1766, Della decimal e delle altre gravezze imposte dal commune di Firenze. Vol. IV (Lisbon e Lucca), reprinted 1967. Bologna, Italy: Fornia Editore.

Vespignani, A. (2009). Predicting the behavior of techno-social systems. Science. 325. 425-428. http://dx.doi.org/10.1126/science. 1171990

Virilio, P. (1994). The vision machine. Trns. by J. Rose. Bloomington, IN: Indiana University Press.

Walcott, C. (1996). Pigeon homing: Observations, experiments and confusions. The Journal of Experimental Biology. 199. 21-27.

Westbrook, J., Mamudi, S., Kishan, S., \& Leising, M. (2014). High-frequency traders find microwaves serve their need for speed. BloombergBusinessweek. July 24. http://www.businessweek.com/articles/2014-07-24/high-frequency-traders-find-microwaves-s uit-their-need-for-speed\#p1

Yin, J., Cao, Y., Hong, H.-L., Ren, J.-G., Lang, H., Liao, S.-K., Zhou, F., Liu, C., Wu, Y.-P., Pan, G.-S., Li, L.,Liu, N.-L., Zhang, Q., Peng, C.-Z., \& Pan, J.-W., \& (2013). Bounding the speed of "spooky action at a distance". Physical Review Letters. 110. 26407(1)-26407(5).

\section{Copyright Disclaimer}

Copyright for this article is retained by the author(s), with first publication rights granted to the journal.

This is an open-access article distributed under the terms and conditions of the Creative Commons Attribution license (http://creativecommons.org/licenses/by/3.0/). 